\title{
Universiteit
}

Leiden

The Netherlands

\section{Natural deep eutectic solvents present in plant exudates? A case study on the saps of Droseraspecies}

Vanda, H.; Mustafa, N.R.; Verpoorte, R.; Klinkhamer, P.G.L.; Choi, Y.H.

\section{Citation}

Vanda, H., Mustafa, N. R., Verpoorte, R., Klinkhamer, P. G. L., \& Choi, Y. H. (2021). Natural deep eutectic solvents present in plant exudates? A case study on the saps of Droseraspecies. Advances In Botanical Research, 97, 253-269. doi:10.1016/bs.abr.2020.09.014

Version: $\quad$ Publisher's Version

License: $\quad$ Licensed under Article 25fa Copyright Act/Law (Amendment Taverne)

Downloaded from: https://hdl.handle.net/1887/3249291

Note: To cite this publication please use the final published version (if applicable). 


\title{
Natural deep eutectic solvents present in plant exudates? A case study on the saps of Drosera species
}

\author{
Henni Vanda ${ }^{a, b}$, Natali Rianika Mustafa ${ }^{a}$, Robert Verpoorte ${ }^{a}$, \\ Peter G.L. Klinkhamer ${ }^{c}$, and Young Hae $\mathrm{Choi}^{\mathrm{a}, *}$ \\ ${ }^{a}$ Natural Products Laboratory, Institute of Biology, Leiden University, Leiden, The Netherlands \\ ${ }^{\mathrm{b}}$ Faculty of Veterinary Medicine, Universitas Syiah Kuala, Banda Aceh, Indonesia \\ ${ }^{c}$ Plant Ecology and Phytochemistry, Institute of Biology, Leiden University, Leiden, The Netherlands \\ *Corresponding author: e-mail address: y.h.choi@biology.leidenuniv.nl
}

\section{Contents}

1. Overview 254

2. Characteristics of plant exudates 255

3. Chemical compositions of plant exudates 257

4. Drosera plant exudate 258

4.1 ${ }^{1} \mathrm{H}$ NMR analysis of Drosera exudate $\quad 259$

4.2 GC-MS analysis Drosera exudates 262

5. Natural deep eutectic solvents formation with the ingredients detected in plant exudates

6. Conclusions 265

References 266

\section{Abstract}

Many plants produce exudates as defense mechanism to hamper pests and pathogens. Plant exudates include latexes, resins, gums, root exudates, and also biofluids produced by carnivorous plants. Plants exudates consist of, among others, polysaccharides, lipids, proteins, organic acids and bases, sugars, and amino acids. All these small molecules are NADES components. In this chapter, the chemical compositions of plant exudates, especially leaf exudates, and Drosera plant biofluids will be elaborated. Metabolic profiling approaches based on ${ }^{1} \mathrm{H}$ NMR and GC-MS were performed on the biofluids of the Drosera species. The ${ }^{1} \mathrm{H}$ NMR spectra showed a high level of myo-inositol and sugars in the biofluids as well as some organic acids. To further confirm the identity of the sugars and to identify some minor components, GC-MS was employed. This gave similar results as the ${ }^{1} \mathrm{H}$ NMR spectroscopy. All the tested exudates were found to contain sugars, such as fructose, glucose, arabinose, sucrose, and xylose; organic acids, such as glucuronic acid and ascorbic acid; and myo-inositol. Those Drosera ingredients are 
known to be strong hydrogen-bond donors. Based on the information obtained from the ${ }^{1} \mathrm{H}$ NMR and GC-MS results, new NADESs compositions were proposed and they were tested in vitro, of which indeed five combinations formed liquids. However, considering that these Drosera biofluids consist mainly of water and other materials, it may indicate that the stable high viscosity droplets typical for the Drosera species must be due in part to other physical-chemical forces, such as gel formation by polysaccharides with calcium ions. A possible role of the NADES-like liquids could be in stabilizing proteins, or the formation of biofilms enabling a faster digesting of the prey. The myoinositol that was clearly a major compound in the exudate might be involved in protecting the leaves and the sugar containing exudate from herbivory. The occurrence of some common products found in fermentation processes might indicate that microorganisms are present in the biofluid.

\section{Overview}

Exudates are produced by various plant species, and have defensive roles against herbivores and environmental stress. These fluids are produced by special cells and released to the surface through interconnected tubes or canals. Plant exudates are, among others in the form of latexes, resins, gums or root exudates, which are locally oozed out where the plant is damaged (Agrawal \& Konno, 2009; Lambert, Wu, \& Santiago-Blay, 2005; Moutim, Silva, Lopes, Fernandes, \& Salas, 1999).

As an example of plant exudates, latex is a creamy milky fluid which is synthesized and stored in laticifer cells and distributed in roots, stems, petioles, and leaves of plants. Plant species that produce latex mainly belong to family Papaveraceae (e.g., Papaver somniferum L.), Euphorbiaceae (e.g., Jathropa curcas L., Hevea brasiliensis (Willd. ex A.Juss.) Müll.Arg., Apocynaceae (e.g., Asclepias syriaca L.), and Moraceae (e.g., Ficus carica L.). Another type of exudate are plant resins which are translucent solutions, insoluble in water, but soluble in various organic solvents. Gums, on the other hand, are water based and contain high molecular weight polysaccharides, some of which are used widely in cosmetics, pharmaceuticals, and food industry (Lambert et al., 2005).

There are also root exudates which consist of organic substances released into the rhizosphere. These exudates serve as an energy source for the microbiome, and to regulate the growth of various microorganisms, to benefit the beneficial microorganisms and reduce levels of potential pathogens (Badri \& Vivanco, 2009; Jaeger, Lindow, Miller, Clark, \& Firestone, 1999).

Another kind of plant exudate consists of the mucilages or biofluids produced by carnivorous plants. This type of biofluids are released to the surface 
of the plant as a trap to catch small animals as their prey. Drosera species are probably the best-known carnivorous plants due to the sticky exudate produced by the glands on the tentacles as trapping mechanism. The glue droplets look like dew on the surface of the tentacles, from which these plants got their name sundew. Once the prey is captured, the leaves will roll-up and perform an outer stomach to cover the prey for enzymatic processing (Barthlott, Porembski, Seine, \& Theisen, 2007).

The enzymatic processing in Drosera species starts when the prey is captured, the sessile glands produce digestive enzymes that will smother the prey, digest it, and provide small nutrient molecules for assimilation in the plant (Barthlott et al., 2007; Matuš́ková et al., 2005; Takeuchi et al., 2011). The enzymatic processes will take approximately $2 \mathrm{~h}$ up to 2 days (Barthlott et al., 2007; Pate \& Dixon, 1978; Schaefer \& Ruxton, 2008).

The fascinating fact about these biofluid is that they remain liquid and do not evaporate easily. It is hypothesized that NADESs may play a role as an alternative liquid to water or lipids. Previous experiments conducted by Choi et al. (2011) showed that many combinations of ubiquitous natural compounds present at high concentrations in all living cells can form a liquid. In this chapter we probe our hypothesis that plant exudates such as latexes, gums, and Drosera mucilages are natural deep eutectic solvents (NADESs) which have the necessary physiological properties such as to protect the plants against various forms of stress (Choi et al., 2011), as well as to dissolve and stabilize enzymes for essential digestive enzymatic processes as in case of Drosera.

\section{Characteristics of plant exudates}

Plant exudates have specific physical and biological characteristics depending on the species. The roles of plant exudates are diverse, and include defense against pests and diseases and allelopathic activity.

Latex is a milky emulsion composed of small organic compounds suspended in a liquid dispersion medium. Not all latexes are whitish, there are some which are transparent or have a distinct color, such as yellow, orange, brown, or red (Abarca, Klinkhamer, \& Choi, 2019; Konno, 2011). Most latexes are sticky and viscous after excretion, and even coagulate and form clots. However, latexes excreted from leaves of the mulberry tree (Morus spp.) and the oleander tree (Nerium oleander L.) are not viscous (Konno, 2011). The chemical properties of latex are related to their functions. Latexes act as the first line of defense against herbivores and pathogens, 
and it also plays a role in environmental stress conditions (Abarca et al., 2019; Agrawal \& Konno, 2009; Konno, 2011). The endophytes living inside the host plant are also believed to contribute via the latex to the production and biotransformation of diverse metabolites related to the plant defense against pests and diseases (Abarca et al., 2019; Kusari, Zühlke, \& Spiteller, 2009; Yang, Rogers, Song, Guo, \& Kolattukudy, 2005).

Resins are exudates produced in specialized surface glands such as glandular hairs or internal ducts. They serve the protection against insects and pathogens. The characteristics of resins are: stable, inert, amorphous, nonvolatile, insoluble in water, but soluble in organic solvents.

Plant root exudates are produced as attractants and repellants in the rhizosphere. The compounds also may regulate the soil microbial community, control the herbivores, facilitate beneficial symbioses, change the chemical and physical properties of the soil, and inhibit the growth of competing plant species (Bais, Weir, Perry, Gilroy, \& Vivanco, 2006; Estabrook \& Yoder, 1998; Nardi et al., 2000).

Plant gums are present in large quantities in a variety of plants, with different structural and metabolic functions. Gums are considered to be pathological products as a result of plant injury or due to drought conditions. Some highly viscous gums, the mucilages, on the other hand, are waterinsoluble, and produced as normal metabolites in epidermal cells of leaves, seed coats, and barks (Bhosale, Osmani, \& Moin, 2014). Both gums and mucilages are translucent amorphous substances, consisting of polymers of a monosaccharide or mixed monosaccharides combined with uronic acids, they may also contain hydrophilic molecules, and when combined with water will form gels (Bhosale et al., 2014; Malsawmtluangi et al., 2014). The gums and mucilages also play a role in the response to the various forms of stress for the plant or plant cells.

Drosera exudates fit best the class of gums. The exudate is transparent, just like drops of glue on the surface of tentacles, and act as trap to catch insects. The trapping mechanism involves two types of glands: stalked glands and sessile glands. Stalked glands specifically secrete a sweet mucilage to attract, capture, and digest the prey, while sessile glands particularly absorb the nutrients. There are different opinions about how the insects are attracted to the plants. Some researchers believe that it is due to the red color of the tentacles that contrast with the background (Schaefer \& Ruxton, 2008), while other researchers believe that the insects are interested in nectar as a source of nutrients, which supports the idea that sugars play an important role in the trapping mechanism (Bennett \& Ellison, 2009). 
Sugars found in the sticky fluid have a particular ratio that may form a NADES that act as a solvent of biomaterials (Choi et al., 2011; Gowda, Reuter, \& Schauer, 1982).

\section{Chemical compositions of plant exudates}

Plant exudates consist of diverse chemicals, including primary metabolites and secondary metabolites. Compared to other plant exudates, latexes have more complex chemical compositions with high concentrations of secondary metabolites, the concentration is even higher than in leaves. Many of these compounds provide resistance to insects and other herbivores by their toxicity, antinutritive effects, or sticky character (Agrawal \& Konno, 2009).

Latexes consist of alkaloids (Itenov, Mølgaard, \& Nyman, 1999; Konno et al., 2006), terpenoids (Rees \& Harborne, 1985; Sessa, Bennett, Lewis, Mansfield, \& Beale, 2000), rubber (Bushman et al., 2006), cardenolides (Dussourd \& Hoyle, 2000; Rasmann, Johnson, \& Agrawal, 2009), and also enzymes such as proteases (John, Bhat, \& Rao, 2003; Rasmann et al., 2009), chitinases (Ramos et al., 2010), and oxidases (Sethi, McAuslane, Rathinasabapathi, Nuessly, \& Nagata, 2009).

Terpenoids are found abundantly in latex, for example, in Euphorbiaceae, phorbol, diterpenes and their derivatives are the major components, which are toxic for insects (Konno, 2011). In the Asteraceae family, several sesquiterpene lactones, including lactucin, lactucopicrin, and 8-deoxylactucin were found (Rees \& Harborne, 1985; Sessa et al., 2000). Cardenolides such as G-strophanthin, voruscharin, ushcharidin, and alotropagenin were found in the Apocynaceae family (Dussourd \& Hoyle, 2000; Rasmann et al., 2009; Samuelsson \& Bohlin, 2009), while toxicariosides was reported in Moraceae family (Carter et al., 1997).

Alkaloids derived from latex are morphine (Hartmann, Schmid, Van Tuinen, \& Berg, 2009; Itenov et al., 1999) and sanguinarine (Tomè \& Colombo, 1995) in Papaveraceae, lobeline in Campanulaceae (Oppel, Dussourd, \& Garimella, 2009), and sugar-mimicking alkaloids in Moraceae (Konno et al., 2006). Most alkaloids are poorly soluble in water, yet they present in numerous plant latex.

Besides secondary metabolites, latexes also contain proteins, such as various types of proteases, protease inhibitors, oxidases, and chitinases. The defensive role of these enzymes on herbivores are unclear, however, it is assumed that they exhibit a toxic effect or hamper the digestion of the plan 
material by targeting to essential proteins in the insects (Zhu-Salzman, $\mathrm{Bi}, \&$ Liu, 2005). In some latexes, these enzymes are bound to carbohydrates, as reported by Odani, Yokokawa, Takeda, Abe, and Odani (1996). The protease inhibitor in latex of Carica papaya L. was bound to two carbohydrate chains, composed of mannose, xylose, fucose, and $\mathrm{N}$-acetylglucosamine residues. A study reported by Hullar and Smith (1966) stated that rubber latex contains myo- and L-inositol, quebrachitol (1-0-methyl-L-inositol), galactinol, and raffinose. Latex of Jatropha neopauciflora $\operatorname{Pax}$ was reported to contain $8.52 \mathrm{mg} / \mathrm{mL}$ carbohydrates, and $79 \%$ of this was fructose (Hernandez-Hernandez et al., 2017). Latex of Jatropha multifida L. was reported to contain multifidol attached to a glucose moiety (Kosasi, Van Der Sluis, \& Labadie, 1989). Barbieri et al. (1983) also reported glucose, galactose, xylose, and fucose in latex of Hura crepitans L. and Euphorbia characias L. All of these sugars are potential candidates for NADESs and might play a role in enzyme preservation, and drought and cold resistance.

Plant resins are composed of mono-, sesqui-, di- and triterpenes (Leonhardt, Schmitt, \& Blüthgen, 2011). Plant gums are usually heteropolysaccharides, consisting of arabinose, galactose, glucose, xylose, mannose, and organic acids (Amid, Mirhosseini, \& Kostadinović, 2012; Amin, Ahmad, Yin, Yahya, \& Ibrahim, 2007; Mirhosseini \& Amid, 2012). Root exudates comprise amino acids, organic acids, phenolics, secondary metabolites, polysaccharides, and also proteins. Though such general qualitative information is available on chemical composition of root exudates from diverse plant species, real in depth studies are lacking for most exudates (Walker, Bais, Grotewold, \& Vivanco, 2003).

\section{Drosera plant exudate}

To learn more about the constituents of Drosera trapping liquids they were collected from seven species of Drosera from the Hortus Botanicus in Leiden. The exudates of Drosera adelae F. Muell., D. regia Stephens, D. capensis L. variety Alba, D. capencis L. variety Rubra, D. capensis L. variety Giant, D. binata Labill., and D. slackii Cheek were collected by microtubes which were prefilled with two solvents, $\mathrm{MeOH}$-aqueous $\mathrm{KH}_{2} \mathrm{PO}_{4}$ buffer $\mathrm{pH} 6$ (4:1) $(\mathrm{v} / \mathrm{v})$ or $\mathrm{KH}_{2} \mathrm{PO}_{4}$ buffer $\mathrm{pH}$ 6. All the samples were dried and further 


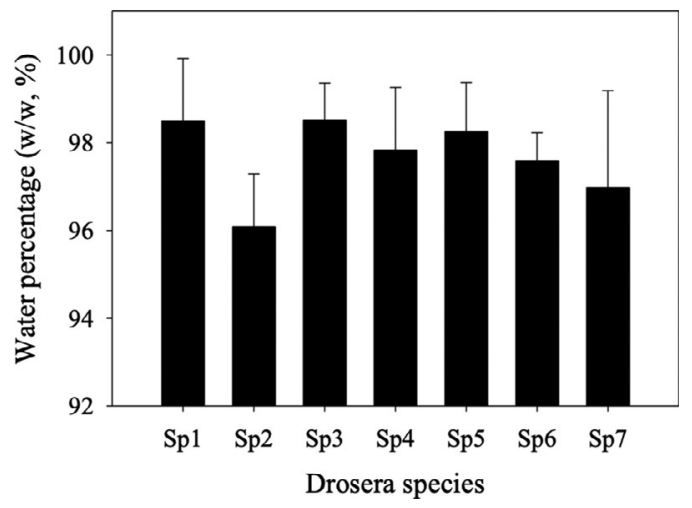

Fig. 1 Water percentage (w/w) of seven Drosera exudates in triplicate collected in June 2013. Sp1 Drosera adelae, Sp2 Drosera regia, Sp3 Drosera capensis Alba, Sp4 Drosera capensis Giant, Sp5 Drosera capensis Rubra, Sp6 Drosera binata, Sp7 Drosera slackii.

analyzed by ${ }^{1} \mathrm{H}$ NMR spectroscopy (Kim, Choi, \& Verpoorte, 2010) and GC-MS to acquire comprehensive qualitative and quantitative data about the exudate's composition.

A water content measurement showed that the average percentage ranged from $96 \%$ to $98.5 \%$ (w/w) (Fig. 1), which makes the exudate suitable for enzymatic processes.

\section{1 ${ }^{1} \mathrm{H}$ NMR analysis of Drosera exudate}

The analysis of the exudates by means of ${ }^{1} \mathrm{H}$ NMR spectroscopy showed that all the Drosera species had myo-inositol as main ingredient. Six species contained sucrose, and five contained glucose (Figs. 2-3). The exudate of D. capensis Rubra was found to have a high level of oligosaccharides. Ethanol was also detected as a major ingredient in all exudates. Acetic-, acetoacetic-, lactic, and formic acid, were detected in all the species in varying concentrations. These compounds are typical products of various fermentation processes and may point to the presence of microorganisms in the biofluid.

Organic acids found in the exudate were citric acid, fumaric acid, and malic acid. Malic acid in D. capensis and D. slackii was higher than in other species, at a molar concentration similar to sucrose (ca. 1:1). The chemical compositions of the exudates are listed in Table 1 , and the average concentration of Drosera biofluids compounds is presented in Fig. 4. 


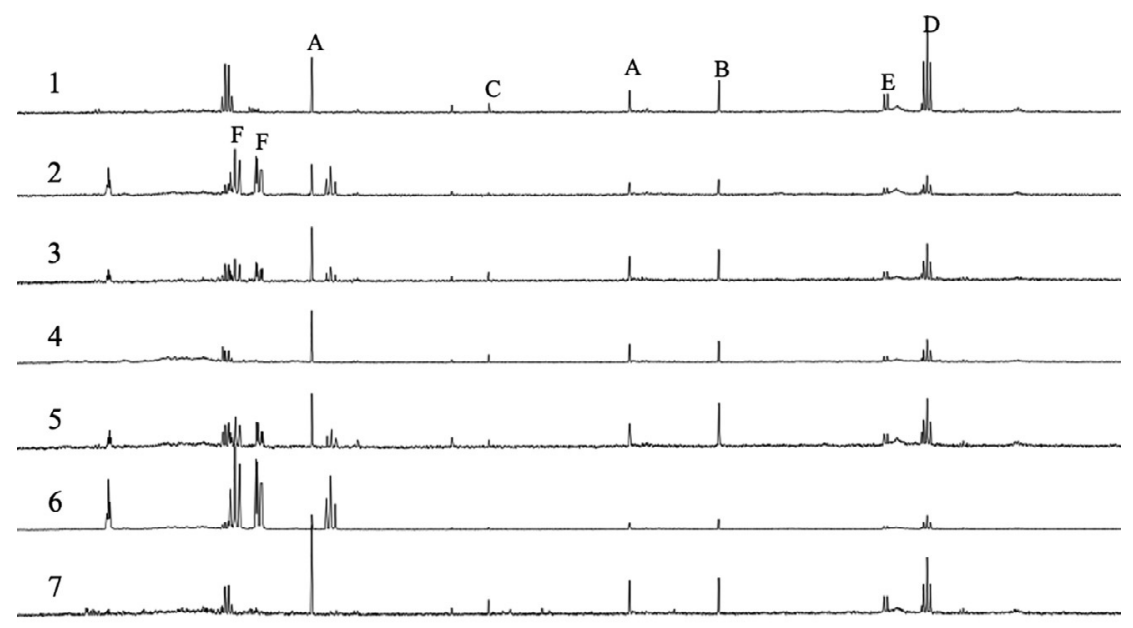

\begin{tabular}{lllllllllllllllllllllll}
\hline 4 & 4.2 & 4.0 & 3.8 & 3.6 & 3.4 & 3.2 & 3.0 & 2.8 & 2.6 & 2.4 & 2.2 & 2.0 & 1.8 & 1.6 & 1.4 & 1.2 & 1.0 & 0.8 & 0.6
\end{tabular}

Chemical shift (ppm)

Fig. $2{ }^{1} \mathrm{H}$ NMR spectra of seven Drosera species $\left(600 \mathrm{MHz}, \mathrm{KH}_{2} \mathrm{PO}_{4}\right.$ buffer containing $0.01 \%$ trimethylsilylpropanoic acid (TMSP, w/w) in the range of $\delta$ 0.3-4.5. 1. Drosera adelae, 2. Drosera regia, 3. Drosera capensis Alba, 4. Drosera capensis Giant, 5. Drosera capensis Rubra, 6. Drosera binata, 7. Drosera slackii. A: acetoacetic acid, B: acetic acid, C: citric acid, D: ethanol, E: lactic acid, F: myo-inositol.

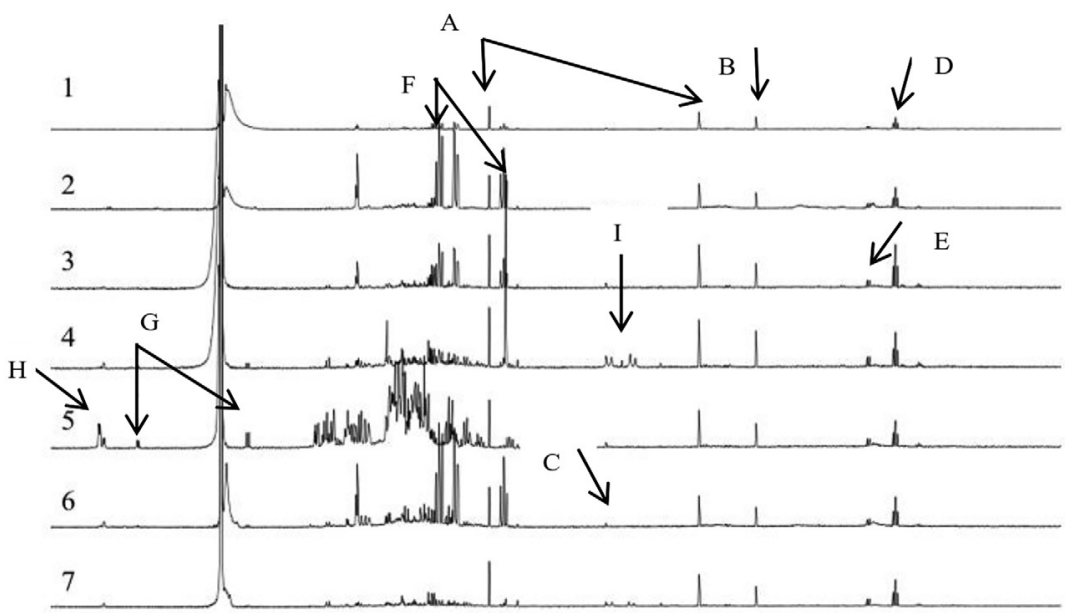

$\begin{array}{llllllllllllllllllllllllllll}5.6 & 5.4 & 5.2 & 5.0 & 4.8 & 4.6 & 4.4 & 4.2 & 4.0 & 3.8 & 3.6 & 3.4 & 3.2 & 3.0 & 2.8 & 2.6 & 2.4 & 2.2 & 2.0 & 1.8 & 1.6 & 1.4 & 1.2 & 1.0 & 0.8 & 0.6 & 0.4\end{array}$

Fig. $3{ }^{1} \mathrm{H}$ NMR spectra of seven Drosera species $\left(600 \mathrm{MHz}, \mathrm{CH}_{3} \mathrm{OH}-d_{4}-\mathrm{KH}_{2} \mathrm{PO}_{4}\right.$ buffer $(8: 2$, $\mathrm{v} / \mathrm{v}$ ) containing $0.01 \%$ trimethylsilylpropanoic acid (TMSP, w/w) in the rage of $\delta 0.3-4.5$. 1. Drosera adelae, 2. Drosera regia, 3. Drosera capensis Alba, 4. Drosera capensis Giant, 5. Drosera capensis Rubra, 6. Drosera binata, 7. Drosera slackii. A: acetoacetic acid, B: acetic acid, C: citric acid, D: ethanol, E: lactic acid, F: myo-inositol, G: glucose, H: sucrose, I: malic acid. 
Table 1 Detected metabolites of Drosera exudates in ${ }^{1} \mathrm{H}$ NMR spectrum $\left[600 \mathrm{MHz}, \mathrm{CH}_{3} \mathrm{OH}-d_{4}-\mathrm{KH}_{2} \mathrm{PO}_{4}\right.$ buffer $(8: 2$, v/v) containing $0.01 \%$ TMSP (w/w)].

\begin{tabular}{|c|c|c|c|c|c|c|c|c|}
\hline \multirow[b]{2}{*}{ Compound } & \multirow{2}{*}{$\begin{array}{l}\text { Characteristic chemical shift in ppm (splitting pattern and } \\
\text { coupling constant in } \mathrm{Hz})^{\mathrm{a}}\end{array}$} & \multicolumn{7}{|c|}{ Drosera species } \\
\hline & & $\mathrm{Sp} 1^{\mathrm{b}}$ & Sp $2^{c}$ & $\mathrm{Sp}^{\mathrm{d}}$ & Sp4 ${ }^{\mathrm{e}}$ & Sp $5^{f}$ & Sp $6^{g}$ & Sp $7^{h}$ \\
\hline Acetoacetic acid & $3.36(\mathrm{~s}), 2.24(\mathrm{~s})$ & + & + & + & + & + & + & + \\
\hline Acetic acid & $1.93(\mathrm{~s})$ & + & + & + & + & + & + & + \\
\hline Citric acid & $2.71(\mathrm{~d}, \mathrm{~J}=16.3), 2.59(\mathrm{~d}, \mathrm{~J}=16.3)$ & & & & + & & & + \\
\hline Ethanol & $3.63(\mathrm{q}, \mathrm{J}=7.1), 1.19(\mathrm{t}, \mathrm{J}=7.1)$ & + & + & + & + & + & + & + \\
\hline Formic acid & $8.5(s)$ & + & + & + & + & + & + & + \\
\hline Fumaric acid & $6.76(\mathrm{~s})$ & & + & & & & & \\
\hline Glucose & $5.23(\mathrm{~d}, \mathrm{~J}=3.9), 4.65(\mathrm{~d}, \mathrm{~J}=8.0)$ & & & + & + & + & + & + \\
\hline myo-Inositol & $3.63(\mathrm{t}, \mathrm{J}=9.54), 3.54(\mathrm{dd}, \mathrm{J}=10.1,3.5)$ & + & + & + & + & + & + & + \\
\hline Sucrose & $5.42(\mathrm{~d}, \mathrm{~J}=3.9), 4.64(\mathrm{~d}, \mathrm{~J}=8.0)$ & & + & + & + & + & + & + \\
\hline Malic acid & $2.6(\mathrm{~d}, \mathrm{~J}=16.9), 2.7(\mathrm{~d}, \mathrm{~J}=16.9)$ & & & & + & & & + \\
\hline Lactic acid & $1.3(\mathrm{~d}, \mathrm{~J}=5.64)$ & + & + & + & + & + & + & + \\
\hline Methanol & $3.35(\mathrm{~s})$ & + & + & + & + & + & + & + \\
\hline
\end{tabular}

${ }^{\mathrm{a}}$ All the chemical shifts were calculated based on $0.00 \mathrm{ppm}$ of TMSP signal, s: singlet, $\mathrm{d}$ : doublet, dd: double doublet, t: triplet, m: multiplet.

${ }^{\mathrm{b}}$ Drosera adelae.

${ }^{\mathrm{c}}$ Drosera regia.

${ }^{\mathrm{d}}$ Drosera capensis Alba.

${ }^{\mathrm{e}}$ Drosera capensis Giant.

${ }^{\mathrm{f}}$ Drosera capensis Rubra

${ }^{\mathrm{g}}$ Drosera binata.

${ }^{\mathrm{h}}$ Drosera slackii. $(n=3)$. 


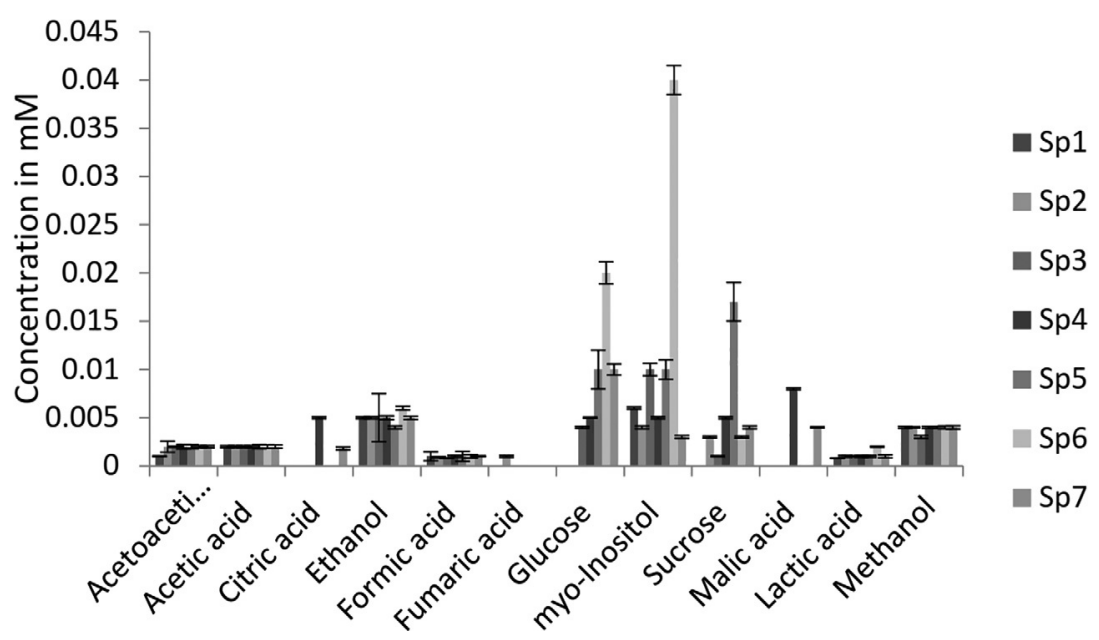

Fig. $4{ }^{1} \mathrm{H}$ NMR average quantification of compounds of Drosera biofluids. Sp1: Drosera adelae, Sp2: Drosera regia, Sp3: Drosera capensis Alba, Sp4: Drosera capensis Giant, Sp5: Drosera capensis Rubra, Sp6: Drosera binata, Sp7: Drosera slackii $(n=3$ with standard deviation).

\subsection{GC-MS analysis Drosera exudates}

${ }^{1} \mathrm{H}$ NMR spectroscopy showed that the main metabolites in Drosera species are organic acids and sugars, which might be components of NADESs. To analyze the chemical composition of the exudates in more detail, gas chromatography-mass spectrometry (GC-MS) was employed after derivatization of non-volatiles. This resulted in the identification of arabinose, fructose, mannose, galactose, sucrose, glucose, xylose, myo-inositol, ascorbic acid, glucuronic acid, and sorbose. In all the exudates, myo-inositol was detected as the main carbohydrate in both buffer and $\mathrm{MeOH}$ extract by GC-MS. Mannose and glucose were found in all $\mathrm{MeOH}$ extracts from the leaves. In buffer extract, fewer compounds were detected, as most of the sugars bind to the resin produced by the glandular hairs of the plants. The non-soluble resin fraction possibly helps keeping up the water content in the exudate and prevents evaporation (Dell, 1977). These results show that all the exudates of the seven species of Drosera have very similar sugar compositions. GC-MS confirmed the presence of myo-inositol in the exudate of all seven Drosera species (Table 2).

Previous experiments on D. capensis (Gowda et al., 1982; Rost \& Schauer, 1977) reported that the exudates contained arabinose, mannose, galactose, xylose, and glucuronic acid, which is similar to our experiment. 
Table 2 Detected metabolites of $\mathrm{MeOH}$ and buffer extracts of Drosera exudates in GC-MS analysis.

$\mathrm{MeOH}$ extract

Buffer extract

\begin{tabular}{|c|c|c|c|c|c|c|c|c|c|c|c|c|c|c|c|}
\hline Compound & Retention time & Sp1 & Sp2 & Sp3 & Sp4 & Sp5 & Sp6 & Sp7 & Sp1 & Sp2 & Sp3 & Sp4 & Sp5 & Sp6 & Sp7 \\
\hline Mannose & 13.15 & + & + & + & & + & + & + & & & + & & & & + \\
\hline myo-inositol & 17.26 & + & + & + & + & + & + & + & + & + & + & + & + & + & ++ \\
\hline Glucose & $15.30 ; 16.16$ & + & + & + & + & + & + & + & & & & & & + & \\
\hline Fructose & 14.37 & & + & + & + & + & & + & & & + & & & & \\
\hline Sorbose & 14.50 & & + & + & & + & + & + & & & & & & & \\
\hline Arabinose & 14.80 & + & & + & + & + & + & + & & + & & + & & + & \\
\hline Galactose & 15.40 & + & + & & & & + & + & & & & & & + & + \\
\hline Ascorbic acid & 15.85 & & + & & & & & & & + & & & & & \\
\hline Glucuronic acid & 16.25 & & & & & + & & & + & & & & & + & + \\
\hline Xylose & 16.39 & & + & + & + & + & + & + & + & + & & & & & ++ \\
\hline Sucrose & 21.7 & + & + & + & + & + & + & + & + & + & & & + & & \\
\hline
\end{tabular}

Sp1: Drosera adelae, Sp2: Drosera regia, Sp3: Drosera capensis Alba, Sp4: Drosera capensis Giant, Sp 5: Drosera capensis Rubra, Sp6: Drosera binata, Sp7: Drosera slackii. 
A study by Kokubun (2017) confirmed that the mucilage of Drosera capensis contain a significant amount of myo-inositol together with polysaccharide, and myo-inositol might act as a cross-linker (hydrogellator) between the polysaccharide strands, probably through the hydrogen bond-network between the hydrogel groups. Huang, Wang, Sun, Agrawal, and Zhang (2015) also reported that Drosera mucilage is a naturally occurring hydrogel, composed of nano particles assembled with polysaccharide, driven by electrostatic interactions mediated with divalent cations $\left(\mathrm{Ca}^{2+}\right.$ and $\left.\mathrm{M}^{\mathrm{g} 2+}\right)$.

\section{Natural deep eutectic solvents formation with the ingredients detected in plant exudates}

From Drosera plant exudate, it is clear that the exudates consist of more than $95 \%$ of water, the very strong hydrogen bonding capacities of the sugars and some of the acids might play role in producing nanoparticles that contain the various enzymes present in the exudate, to encapsulate proteins that might be more stable than in normal water solutions, or to adsorb on the prey to help to dissolve the prey for further digesting by the enzymes. To see if any of the ingredients may form NADESs we tested some potential NADESs, which could be formed by the small molecules present in the Drosera biofluids.

The NADESs were prepared with myo-inositol combined with various sugars and acids, because myo-inositol was found in all Drosera species. However, none of the combinations tested was able to form a liquid, therefore a non-organic ingredient, $\mathrm{Ca}^{2+}$ was added, in a form of $\mathrm{CaCl}_{2} \cdot 2 \mathrm{H}_{2} \mathrm{O}$, as this component was the main cation found in D. capensis and D. binata (Huang et al., 2015; Rost \& Schauer, 1977). All of the components were mixed together according to Choi et al. (2011) and with certain molar ratios, NADESs were formed. The tested combinations are shown in Table 3.

Other combinations were made of a number of sugars in combination with organic acids, which refers to previous experiments by Gowda et al. $(1982,1983)$. The combinations included arabinose, xylose, galactose, mannose, glucuronic acid, and water with a molar ratio of 3.6:1:4.9:8.4:8.2:80, with a water concentration of about $23 \%$ were all a liquid. A different molar ratio 8.4:1:9.6:18.3:17.1:60, with $10 \%$ of water also gave a liquid. The combinations which gave liquids stayed liquid even after freeze-drying. The viscosity of the fluid decreased when more water was added. 
Table 3 Composition and ratios of compounds tested for the formation of NADESs (based on the analysis of the Drosera samples: Gowda et al., 1982; Gowda, Reuter, \& Schauer, 1983, this chapter).

\begin{tabular}{|c|c|c|}
\hline Composition & Mole ratio & Result \\
\hline Myo-inositol:sucrose:water & $1: 2: 5$ & Solid \\
\hline Myo-inositol:sucrose: $\mathrm{CaCl}_{2} \bullet 2 \mathrm{H}_{2} \mathrm{O}$ : water & $1: 2: 2: 20$ & Liquid \\
\hline D-mannose:glucose:choline chloride:water & $1: 2: 1: 2$ & Liquid \\
\hline D-mannose:D-glucuronic acid:betaine:water & $1: 1: 1: 4$ & Liquid \\
\hline Myo-inositol:malic acid:water & $1: 2: 2$ & Solid \\
\hline $\begin{array}{l}\text { Myo-inositol:glucose:malic acid:choline chloride: } \\
\text { water }\end{array}$ & $1: 1: 1: 2$ & Solid \\
\hline Arabinose:D-mannose:Myo-inositol:water & $2: 1: 1: 5$ & Solid \\
\hline Myo-inositol:acetic acid:water & $1: 1: 5$ & Solid \\
\hline Myo-inositol:formic acid:water & $1: 2: 5$ & Solid \\
\hline $\begin{array}{l}\text { D-arabinose:D-xylose:D-galactose:D-mannose: } \\
\text { D-glucuronic acid:water }\end{array}$ & $8.4: 1: 9.6: 18.3: 17.1: 60$ & Liquid \\
\hline $\begin{array}{l}\text { D-arabinose:D-xylose:D-galactose:D-mannose: } \\
\text { D-glucuronic acid:water }\end{array}$ & 3.6:1:4.9:8.4:8.2:80 & Liquid \\
\hline
\end{tabular}

Sugar-based NADESs usually have thicker, more viscous consistency. Using the ingredients found in the biofluids plus choline chloride or betaine were tested for the formation of less viscous NADESs.

\section{Conclusions}

Exudates are thought to protect the producing plants against herbivores, insects, and pathogens. They have similar physical and chemical characteristics; however, the roles of plant exudates are diverse, and depends on the plant species. Plant exudates are mainly composed of sugars, amino acids, and organic acids, which may constitute a NADES. They also contain secondary metabolites, water, and minerals. In case of insect catching Drosera species, ${ }^{1} \mathrm{H}$ NMR and GC-MS were used to analyze metabolites in the exudates of seven Drosera species. The NMR results were confirmed by the results of $\mathrm{GC}-\mathrm{MS}$, which also resulted in the identification of some minor sugars in all exudates. The role of the compounds found could be 
for stabilization of the proteins or the formation of biofilms around the caught preys enabling a faster enzymatic digesting of the prey. The Drosera biofluids consist of 95-99\% water, and their viscosity and stability are preserved without water loss over prolonged periods. As NADESs seem not to be a primary factor in this special behavior of the Drosera biofluids, other explanations need to be explored in future research. The role of the compounds found in the Drosera biofluid could be an antifeedant activity against herbivores, the attraction of their preys, stabilization of the proteins or the formation of biofilms around the caught preys enabling a faster enzymatic digesting of the prey. Calcium alginate is a well-known example of a gel formed from a polysaccharide, which is used to immobilize enzymes or cells in various biotechnological applications. Taking that as an example the combination of polysaccharide and/or proteins with cations might play a role in keeping the Drosera biofluids in a highly viscous liquid state. Finally, the occurrence of ethanol, acetoacetic acid, acetic acid and lactic acid as typical products of various fermentation processes may point to the presence of one or more microorganisms in the biofluid.

\section{References}

Abarca, L. F. S., Klinkhamer, P. G., \& Choi, Y. H. (2019). Plant latex, from ecological interests to bioactive chemical resources. Planta Medica, 85, 856-868.

Agrawal, A. A., \& Konno, K. (2009). Latex: A model for understanding mechanisms, ecology, and evolution of plant defense against herbivory. Annual Review of Ecology, Evolution, and Systematics, 40, 311-331.

Amid, B. T., Mirhosseini, H., \& Kostadinović, S. (2012). Chemical composition and molecular structure of polysaccharide-protein biopolymer from Durio zibethinusseed: Extraction and purification process. Chemistry Central Journal, 6, 117.

Amin, A. M., Ahmad, A. S., Yin, Y. Y., Yahya, N., \& Ibrahim, N. (2007). Extraction, purification and characterization of durian (Durio zibethinus) seed gum. Food Hydrocolloids, 21, 273-279.

Badri, D. V., \& Vivanco, J. M. (2009). Regulation and function of root exudates. Plant, Cell \& Environment, 32, 666-681.

Bais, H. P., Weir, T. L., Perry, L. G., Gilroy, S., \& Vivanco, J. M. (2006). The role of root exudates in rhizosphere interactions with plants and other organisms. Annual Review of Plant Biology, 57, 233-266.

Barbieri, L., Falasca, A., Franceschi, C., Licastro, F., Rossi, C. A., \& Stirpe, F. (1983). Purification and properties of two lectins from the latex of the euphorbiaceous plants Hura crepitans L. (sand-box tree) and Euphorbia characias L. (Mediterranean spurge). Biochemical Journal, 215, 433-439.

Barthlott, W., Porembski, S., Seine, R., \& Theisen, I. (2007). The curious world of carnivorous plants: A comprehensive guide to their biology and cultivation. Portland, Or: Timber Press.

Bennett, K. F., \& Ellison, A. M. (2009). Nectar, not colour, may lure insects to their death. Biology Letters, 5, 469-472.

Bhosale, R. R., Osmani, R. A. M., \& Moin, A. (2014). Natural gums and mucilages: A review on multifaceted excipients in pharmaceutical science and research. International Journal of Pharmacognosy and Phytochemical Research, 15(4), 901-912. 
Bushman, B. S., Scholte, A. A., Cornish, K., Scott, D. J., Brichta, J. L., Vederas, J. C., et al. (2006). Identification and comparison of natural rubber from two Lactuca species. Phytochemistry, 67, 2590-2596.

Carter, C. A., Forney, R. W., Gray, E. A., Gehring, A. M., Schneider, T. L., Young, D. B., et al. (1997). Toxicarioside a. a new cardenolide isolated from Antiaris toxicaria latexderived dart poison. Assignment of the $1 \mathrm{H}$-and 13C-NMR shifts for an antiarigenin aglycone. Tetrahedron, 53, 13557-13566.

Choi, Y. H., van Spronsen, J., Dai, Y., Verberne, M., Hollmann, F., Arends, I. W. C. E., et al. (2011). Are natural deep eutectic solvents the missing link in understanding cellular metabolism and physiology? Plant Physiology, 156, 1701-1705.

Dell, B. (1977). Distribution and function of resins and glandular hairs in Western Australian plants. Journal of the Royal Society of Western Australia, 59, 119-123.

Dussourd, D. E., \& Hoyle, A. M. (2000). Poisoned plusiines: Toxicity of milkweed latex and cardenolides to some generalist caterpillars. Chemoecology, 10, 11-16.

Estabrook, E. M., \& Yoder, J. I. (1998). Plant-plant communications: Rhizosphere signaling between parasitic angiosperms and their hosts. Plant Physiology, 116, 1-7.

Gowda, D. C., Reuter, G., \& Schauer, R. (1982). Structural features of an acidic polysaccharide from the mucin of Drosera binata. Phytochemistry, 21, 2297-2300.

Gowda, D. C., Reuter, G., \& Schauer, R. (1983). Structural studies of an acidic polysaccharide from the mucin secreted by Drosera capensis. Carbohydrate Research, 113, 113-124.

Hartmann, A., Schmid, M., Van Tuinen, D., \& Berg, G. (2009). Plant-driven selection of microbes. Plant and Soil, 321, 235-257.

Hernandez-Hernandez, A. B., Alarcon-Aguilar, F. J., Almanza-Perez, J. C., Nieto-Yañez, O., Olivares-Sanchez, J. M., Duran-Diaz, A., et al. (2017). Antimicrobial and antiinflammatory activities, wound-healing effectiveness and chemical characterization of the latex of Jatropha neopanciflora Pax. Journal of Ethnopharmacology, 204, 1-7.

Huang, Y., Wang, Y., Sun, L., Agrawal, R., \& Zhang, M. (2015). Sundew adhesive: A naturally occurring hydrogel. Journal of the Royal Society Interface, 12, 20150226.

Hullar, T. L., \& Smith, F. (1966). The neutral carbohydrates of ammoniated rubber latex. Archives of Biochemistry and Biophysics, 115, 505-509.

Itenov, K., Mølgaard, P., \& Nyman, U. (1999). Diurnal fluctuations of the alkaloid concentration in latex of poppy Papaver somniferum is due to day-night fluctuations of the latex water content. Phytochemistry, 52, 1229-1234.

Jaeger, C. H., Lindow, S. E., Miller, W., Clark, E., \& Firestone, M. K. (1999). Mapping of sugar and amino acid availability in soil around roots with bacterial sensors of sucrose and tryptophan. Applied and Environmental Microbiology, 65, 2685-2690.

John, K. S., Bhat, S. G., \& Rao, U. P. (2003). Biochemical characterization of sap (latex) of a few Indian mango varieties. Phytochemistry, 62, 13-19.

Kim, H. K., Choi, Y. H., \& Verpoorte, R. (2010). NMR-based metabolomic analysis of plants. Nature Protocols, 5, 536-549.

Kokubun, T. (2017). Occurrence of myo-inositol and alkyl-substituted polysaccharide in the prey-trapping mucilage of Drosera capensis. The Science of Nature, 104, 83.

Konno, K. (2011). Plant latex and other exudates as plant defense systems: Roles of various defense chemicals and proteins contained therein. Phytochemistry, 72, $1510-1530$.

Konno, K., Ono, H., Nakamura, M., Tateishi, K., Hirayama, C., Tamura, Y., et al. (2006). Mulberry latex rich in antidiabetic sugar-mimic alkaloids forces dieting on caterpillars. Proceedings of the National Academy of Sciences, 103, 1337-1341.

Kosasi, S., Van Der Sluis, W. G., \& Labadie, R. (1989). Multifidol and multifidol glucoside from the latex of Jatropha multifida. Phytochemistry, 28, 2439-2441.

Kusari, S., Zühlke, S., \& Spiteller, M. (2009). An endophytic fungus from Camptotheca acuminata that produces camptothecin and analogues. Journal of Natural Products, 72, 2-7. 
Lambert, J. B., Wu, Y., \& Santiago-Blay, J. A. (2005). Taxonomic and chemical relationships revealed by nuclear magnetic resonance spectra of plant exudates. Journal of Natural Products, 68, 635-648.

Leonhardt, S. D., Schmitt, T., \& Blüthgen, N. (2011). Tree resin composition, collection behavior and selective filters shape chemical profiles of tropical bees (Apidae: Meliponini). PLoS One, 6, e23445.

Malsawmtluangi, C., Thanzami, K., Lalhlenmawia, H., Selvan, V., Palanisamy, S., Kandasamy, R., et al. (2014). Physicochemical characteristics and antioxidant activity of Prunus cerasoides D. Don gum exudates. International Journal of Biological Macromolecules, 69, 192-199.

Matušíková, I., Salaj, J., Moravčíková, J., Mlynárová, L., Nap, J.-P., \& Libantová, J. (2005). Tentacles of in vitro-grown round-leaf sundew (Drosera rotundifolia. L.) show induction of chitinase activity upon mimicking the presence of prey. Planta, 222, 1020-1027.

Mirhosseini, H., \& Amid, B. T. (2012). A review study on chemical composition and molecular structure of newly plant gum exudates and seed gums. Food Research International, 46, 387-398.

Moutim, V., Silva, L. G., Lopes, M. T. P., Fernandes, G. W., \& Salas, C. E. (1999). Spontaneous processing of peptides during coagulation of latex from Carica papaya. Plant Science, 142, 115-121.

Nardi, S., Concheri, G., Pizzeghello, D., Sturaro, A., Rella, R., \& Parvoli, G. (2000). Soil organic matter mobilization by root exudates. Chemosphere, 41, 653-658.

Odani, S., Yokokawa, Y., Takeda, H., Abe, S., \& Odani, S. (1996). The primary structure and characterization of carbohydrate chains of the extracellular glycoprotein proteinase inhibitor from latex of Carica papaya. European Journal of Biochemistry, 241, 77-82.

Oppel, C. B., Dussourd, D. E., \& Garimella, U. (2009). Visualizing a plant defense and insect counterploy: Alkaloid distribution in Lobelia leaves trenched by a plusiine caterpillar. Journal of Chemical Ecology, 35, 625-634.

Pate, J., \& Dixon, K. (1978). Mineral nutrition of Drosera erythrorhiza Lindl. With special reference to its tuberous habit. Australian Journal of Botany, 26, 455-464.

Ramos, M. V., Grangeiro, T. B., Freire, E. A., Sales, M. P., Souza, D. P., Araújo, E. S., et al. (2010). The defensive role of latex in plants: Detrimental effects on insects. ArthropodPlant Interactions, 4, 57-67.

Rasmann, S., Johnson, M. D., \& Agrawal, A. A. (2009). Induced responses to herbivory and jasmonate in three milkweed species. Journal of Chemical Ecology, 35, 1326.

Rees, S. B., \& Harborne, J. B. (1985). The role of sesquiterpene lactones and phenolics in the chemical defence of the chicory plant. Phytochemistry, 24, 2225-2231.

Rost, K., \& Schauer, R. (1977). Physical and chemical properties of the mucin secreted by Drosera capensis. Phytochemistry, 16, 1365-1368.

Samuelsson, G., \& Bohlin, L. (2009). Drugs of natural origin $\left(6^{\text {th }}\right.$ edition, pp. 470-471). Stockholm, Sweden: Swedish Pharmaceutical Press.

Schaefer, H. M., \& Ruxton, G. D. (2008). Fatal attraction: Carnivorous plants roll out the red carpet to lure insects. Biology Letters, 4, 153-155.

Sessa, R. A., Bennett, M. H., Lewis, M. J., Mansfield, J. W., \& Beale, M. H. (2000). Metabolite profiling of sesquiterpene lactones from Lactuca species major latex components are novel oxalate and sulfate conjugates of lactucin and its derivatives. Journal of Biological Chemistry, 275, 26877-26884.

Sethi, A., McAuslane, H. J., Rathinasabapathi, B., Nuessly, G. S., \& Nagata, R. T. (2009). Enzyme induction as a possible mechanism for latex-mediated insect resistance in romaine lettuce. Journal of Chemical Ecology, 35, 190-200. 
Takeuchi, Y., Salcher, M. M., Ushio, M., Shimizu-Inatsugi, R., Kobayashi, M. J., Diway, B., et al. (2011). In situ enzyme activity in the dissolved and particulate fraction of the fluid from four pitcher plant species of the genus nepenthes. PLoS One, 6, 1-9.

Tomè, F., \& Colombo, M. L. (1995). Distribution of alkaloids in Chelidonium majus and factors affecting their accumulation. Phytochemistry, 40, 37-39.

Walker, T. S., Bais, H. P., Grotewold, E., \& Vivanco, J. M. (2003). Root exudation and rhizosphere biology. Plant Physiology, 132, 44-51.

Yang, Z., Rogers, L. M., Song, Y., Guo, W., \& Kolattukudy, P. E. (2005). Homoserine and asparagine are host signals that trigger in planta expression of a pathogenesis gene in Nectria haematococca. Proceedings of the National Academy of Sciences, 102, 4197-4202.

Zhu-Salzman, K., Bi, J. L., \& Liu, T. X. (2005). Molecular strategies of plant defense and insect counter-defense. Insect Sci., 12, 3-15. 